\title{
Building of a Mathematical Model for the Reduction of Iron Ore in Ore/Coal Composites
}

\author{
S. SUN and W.-K. LU' \\ Formerly Department of Materials Science and Engineering, McMaster University. Now at Dofasco Inc., Box 2460, Hamilton, \\ Ontario, L8N 3J5, Canada. \\ 1) Department of Materials Science and Engineering, McMaster University, Hamilton,
} Ontario, L8S 4L7, Canada.

(Received on August 20, 1998; accepted in final form on October 25, 1998)

\begin{abstract}
A non-isothermal and non-isobaric mathematical model which consists of 19 independent equations, was developed for the study of the kinetics of reduction iron ore in an ore/coal composite, based on experimental condition with furnace temperature of $1200^{\circ} \mathrm{C}$ and ore/coal ratio of $80 / 20$. This model has been applied to the other three sets of independent experiments different in furnace temperatures $\left(1300^{\circ} \mathrm{C}\right)$ and ore/coal ratios $(82 / 18$ and $85 / 15)$ for its validation. General agreement between the computed and measured temperatures, the degree of reduction and the degree of carbon gasification as functions of reaction time and location illustrates that this mathematical model is capable of representing data observed in this system.
\end{abstract}

KEY WORDS: mathematical model; kinetics; reduction; mass and heat transfer; iron ore; pulverized coal.

\section{Introduction}

In the last two decades, in the search of a coke-free and environmentally friendly ironmaking process, it is desirable to have following characteristics: (i) coal-based, (ii) without high temperature raw material preparation steps such as cokemaking and sintering, and (iii) low coal rate. It has led to the suggestion that it should start with a thoroughly mixed iron ore fines and pulverized coal to avoid the agglomeration as well as to take advantages of large specific surface of both solids and very short distance for reacting gases to reach either solids.

Extensive researches have been conducted to study the kinetics and mechanisms in the iron ore/coal system. ${ }^{1-11}$ ) In most of studies reported in the literature, the specimen of iron oxide (hematite or magnetite)/carbon (coke, char or coal) mixture was prepared in the form of pellets. Weight-loss method was commonly used for measurement of the rate of reaction.

These experiments provided a qualitative understanding of these reacting system. However, quantitative information, particularly with respect to the temperature variations and composition changes within the specimen as functions of reaction time, were not available in these investigations. As the result, only simple isothermal mathematical models ${ }^{2,6,7)}$ could be proposed for the study.

Recognizing that heat transfer with the reacting system due to highly endothermic carbon gasification would have important effect on the rate of reaction, Seaton $e t$ al. ${ }^{6)}$ observed temperature difference between surface and centre of pellets by placing thermocouples at these locations. Bryk and $\mathrm{Lu}^{9)}$ observed gradients of temperature and degree of metallization along the radial direction of an ore/coal mixture packed in a steel crucible. These results confirmed that for this non-isothermal reacting system heat transfer should be a part of the kinetic study.

Huang and $\mathrm{Lu}^{11)}$ designed their experiments with a crucible $118 \mathrm{~mm}$ in diameter so that in-site temperature measurements by buried thermocouples could be done. Sun and $\mathrm{Lu}^{12)}$ developed a non-isothermal mathematical based on Huang and Lu's experimental data. The model includes heat and mass transfer and offers a better understanding of the reacting system. However, due to the size of the crucible, chemical reactions in the interior continued for a few minutes when the crucible was being cooled after removal from furnace, significant error existed in results of chemical analysis of the partially reacted product at interior locations. As a continuing effort in the study of the iron ore/coal system, an improved one-dimensional reactor including in-situ measurements of temperature and gas pressure was design for a better control of directions of heat and gas flows, more effective in stopping chemical reactions at the end of an experiment, as well as simplification of mathematical computation. And a non-isothermal and non-isobaric model was developed. Experimental results of this study have been documented in a thesis ${ }^{13)}$ and published in a paper. ${ }^{14)}$ The development of a mathematical model and its validation is reported in the present work. The application of this model in the field of iron ore reduction in ore/coal mixtures is documented in an 


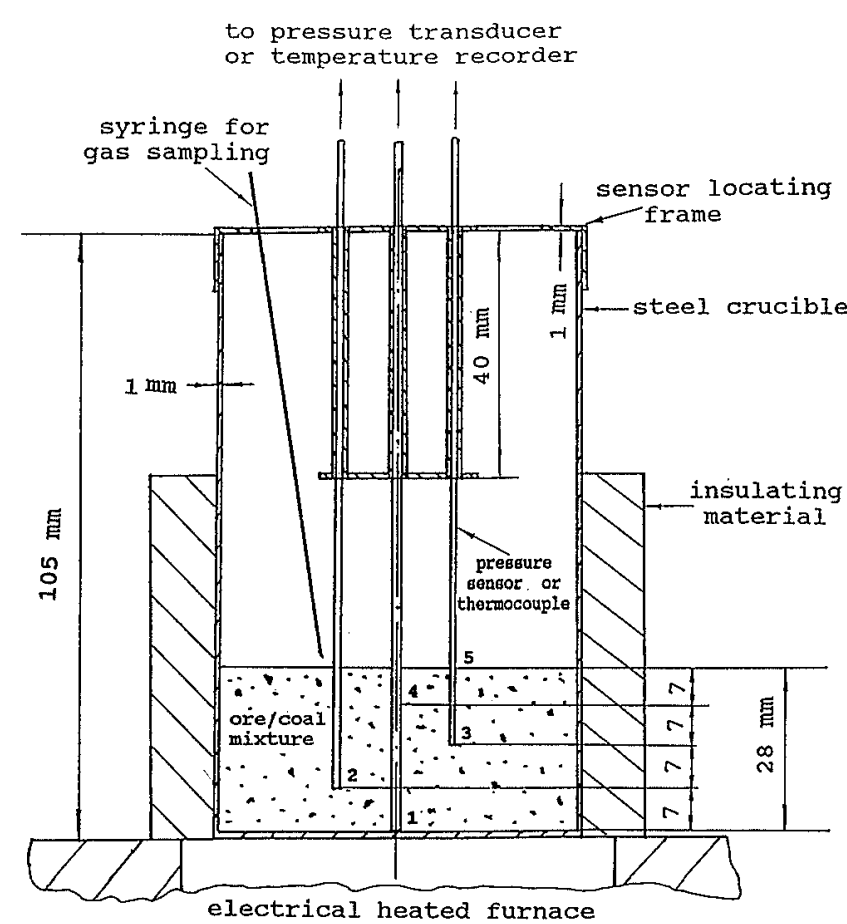

Fig. 1. Schematic diagram of the experimental apparatus.

accompanying paper. ${ }^{15)}$

\section{Experimental Investigation}

Experimental investigation has been reported in details in Refs. 13) and 14). The following is an outline of this work needed to appreciate the building of the mathematical model.

A one-dimensional experimental system was designed for its simplicity in both measurements and modelling. It consists of a cylindrical stainless steel crucible $(0.105 \mathrm{~m}$ in height and $0.058 \mathrm{~m}$ i.d.) and sensors for in-situ measurements of temperatures and gaseous pressures, as shown in Fig. 1. Five thermocouple or pressure sensors are embedded along the height of the packing from bottom to top at every $7 \mathrm{~mm}$ vertical distance as shown in Fig. 1. The terms "Location 1, 2, 3, 4 and 5" used to display the experimental results signify the location at the same height where the corresponding sensor is embedded. The sixth thermocouple was placed at the outer surface of the crucible bottom to monitor the furnace temperature. The raw materials used in these experiments were magnetite concentrate and high volatile coal.

In most experiments, dried concentrate and pulverized coal were mixed at an ore/coal ratio of $80 / 20$ by weight, and packed in the steel crucible with a packing density of $1900 \mathrm{~kg} / \mathrm{m}^{3}$. Experiments were conducted with the furnace temperature set at 1200 and $1300^{\circ} \mathrm{C}$. At the end of an experiment, the crucible was quickly removed from the furnace and quenched by running water over the bare wall of the crucible to stop the reactions in the mixture. Samples for chemical analysis were taken at each location at the same height as thermocouples and pressure probes by careful removal of the partially reacted mixture, layer by layer, from the top. Typical experimental results are shown in Figs. $\mathbf{2}$ to $\mathbf{5}$ with data points for the same

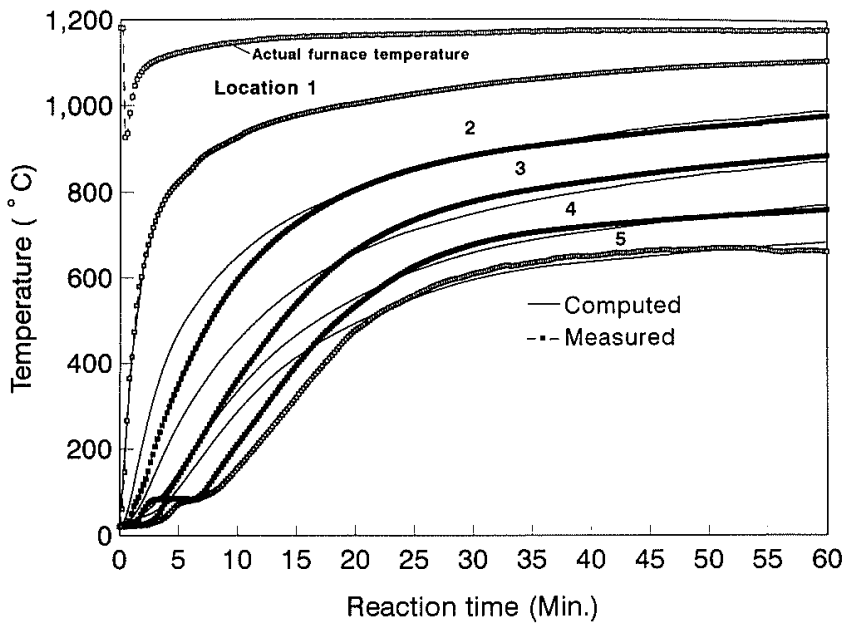

Fig. 2. Measured and computed temperature as a function of reaction time (Ore/coal $=80 / 20$, furnace temperature $=1200^{\circ} \mathrm{C}$ ).

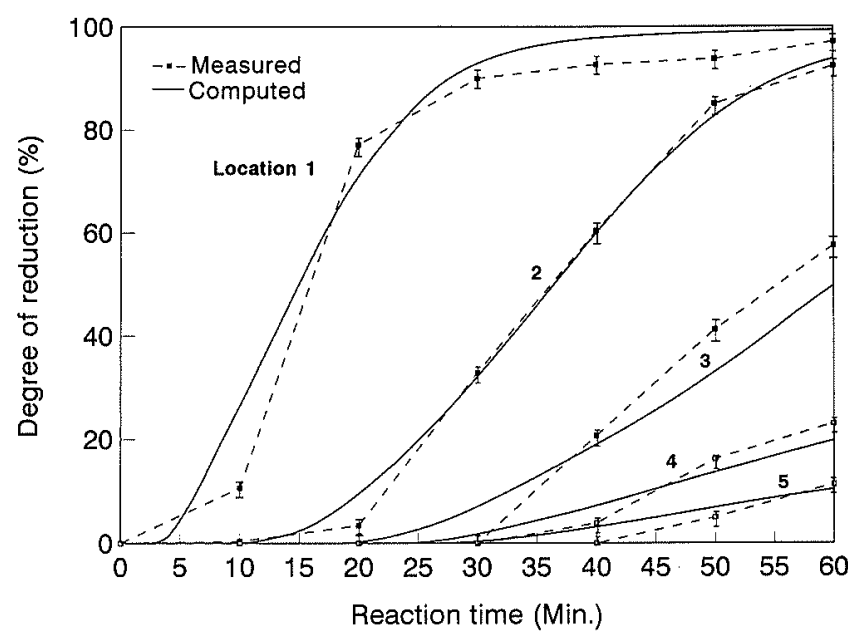

Fig. 3. Degree of reduction as a function of reaction time (Ore $/$ coal $=80 / 20$, furnace temperature $=1200^{\circ} \mathrm{C}$ ).

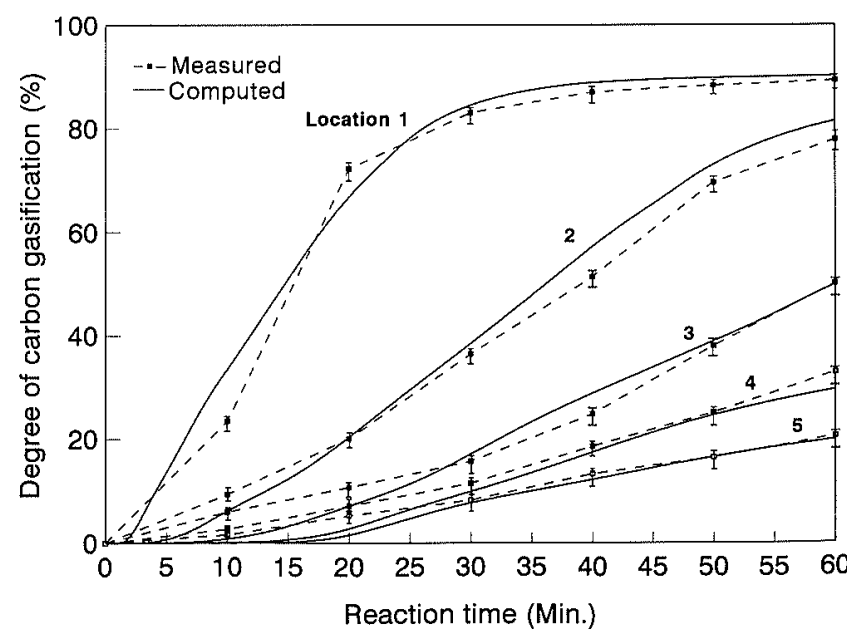

Fig. 4. Degree of carbon gasification as a function of reaction time (Ore $/$ coal $=80 / 20$, furnace temperature $=$ $\left.1200^{\circ} \mathrm{C}\right)$

location connected by dot line. The dot lines are used for visual presentation without any scientific implications. Details of the experimental procedures and results are available elsewhere. ${ }^{13)}$ 


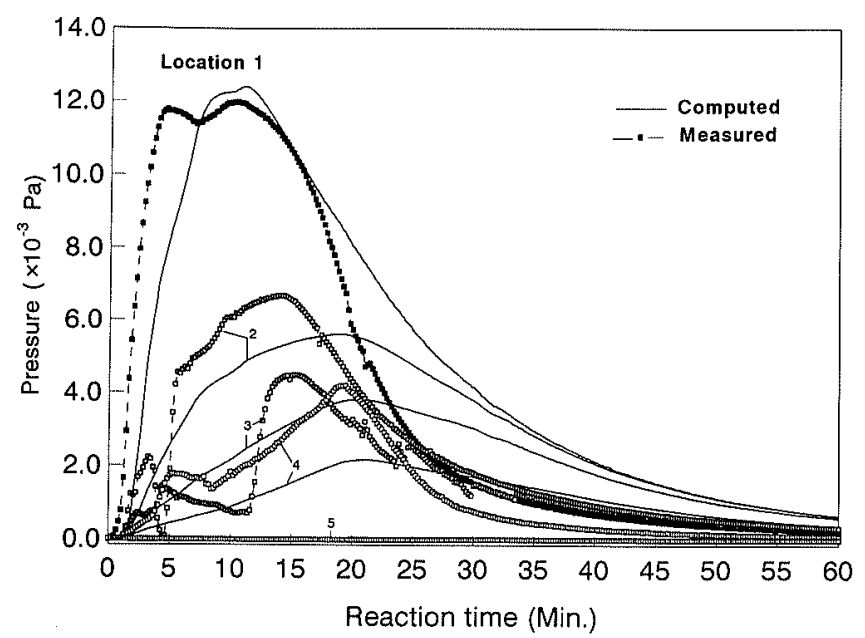

Fig. 5. Measured and computed local pressure as a function of reaction time (Ore/coal $=80 / 20$, furnace temperature $=1200^{\circ} \mathrm{C}$ ).

\section{Mathematical Modelling}

A non-isothermal and non-isobaric mathematical model for reactions in this system has been developed. It includes: one equation of thermal energy balance, nine kinetic expressions for heterogeneous reactions, six equations of mass balance for gaseous species, one continuity equation, one momentum equation and one equation of state for ideal gases. These 19 independent equations are solved simultaneously by numerical methods to give local values of 19 variables (temperature, rates of reactions, composition of solids, pressure, velocity of gas flow, and concentrations of gases) as functions of time and distance from the hot face in the axial direction of the cylindrical system.

\subsection{Heat Transfer within A Porous Medium}

In a porous medium or a packed bed, heat transfer is active not only within each phase (solid and gaseous phases), but also between phases. In the present ore/coal mixture, there exits a very large area of solid surface (about $95000 \mathrm{~m}^{2} / \mathrm{m}^{3}$ of bed), which gives an extensive gas-solid contact in the packed bed. Subsequently, the rate of heat transfer between solid and gas phases is relatively high; therefore, the gas temperature may be assumed to be equal to that of solid at the same location.

The equations for heat transfer in a porous medium, in principle, should include conductive, radiant and convective terms. The relative importance of these mechanisms varies, which depends on solid properties, pore structure, temperature range and gas flow. A numerical evaluation of conduction and radiation heat transfer shows that under present experimental conditions, rate of conduction is three orders of magnetite gteater than that of radiation; therefore, radiation heat transfer may be neglected without introducing significant error in computation. ${ }^{13)}$ Thus the equation for heat transfer is in the form of heat conduction and convection, with heat of chemical reactions as the source and sink terms, as follows:

$$
\begin{aligned}
\frac{\partial}{\partial t}\left(\rho_{\mathrm{m}} C_{\mathrm{pm}} T\right)= & \frac{\partial}{\partial x}\left(K_{\mathrm{cffm}} \frac{\partial T}{\partial x}\right) \\
& -\sum_{i} \dot{R}_{i} \Delta H_{i}-\frac{\partial}{\partial x}\left(\rho_{\mathrm{g}} V_{\mathrm{o}} C_{\mathrm{pg}} T\right)
\end{aligned}
$$

\subsection{Rate Equations for Heterogeneous Chemical Reac- tions}

The important chemical reactions in a mixture of magnetite concentrate and coal are:

(a) Iron ore reduction by $\mathrm{CO}$ (or by $\mathrm{H}_{2}$ ):

$$
\begin{gathered}
\mathrm{Fe}_{3} \mathrm{O}_{4}+4 \mathrm{CO}=3 \mathrm{Fe}+4 \mathrm{CO}_{2} \text { when } T<570^{\circ} \mathrm{C} \\
\mathrm{Fe}_{3} \mathrm{O}_{4}+\mathrm{CO}=3 \mathrm{FeO}+\mathrm{CO}_{2} \text { when } T \geq 570^{\circ} \mathrm{C} \\
\mathrm{FeO}+\mathrm{CO}=\mathrm{Fe}+\mathrm{CO}_{2} \text { when } T \geq 570^{\circ} \mathrm{C} \ldots
\end{gathered}
$$

and Eqs. (2A), (3A) and (4A) with $\mathrm{H}_{2}$ as the reductant.

(b) Coal devolatilization:

$$
\text { Coal } \rightarrow \mathrm{C}+\text { volatile matter }
$$

(c) Carbon gasification:

$$
\mathrm{C}+\mathrm{CO}_{2}=2 \mathrm{CO}
$$

and Eq. (6A) with $\mathrm{H}_{2} \mathrm{O}$ as the oxidant.

For a gas-solid reaction of individual particles of iron ore or char, the shrinking core model for reversible reaction is used. The rate of the topochemical reaction is both proportional to reacting gas-solid interfacial area, and a first order reaction with respect to the concentration of gaseous reactants. This model implies that the number of particles of ore and their shape and size do not change during the course of reaction. As the number of particles and average surface area of individual particles per unit volume of the porous medium can be estimated by characterization of raw materials, the units for rate equations can be expressed in moles per unit volume of porous medium per unit time. Since the reacting mixture is made of very fine particles (about $3.9 \times 10^{-5} \mathrm{~m}$ in diameter), the movement of gaseous molecules through porous product layers of the particles are over a very short distance. It would be reasonable to assume that mass transfer through the product layers will not contribute significant resistance to the rate of the overall reactions, in comparison to that of the interfacial reactions. With these assumptions, the rate equations for these reactions may be derived in following sections.

\subsubsection{Iron Oxide Reductions}

The iron oxide reduction takes place simultaneously and independently by both $\mathrm{CO}$ and $\mathrm{H}_{2}$ as both reductants are present in the system. The observed rate of reduction is the sum of that by these two gaseous reductants as shown below:

$$
\dot{R}_{i}=\dot{R}_{j}^{\mathrm{CO}}+\dot{R}_{i}^{\mathrm{H}_{2}}
$$

According to the un-reacted core model, the rate of iron oxides reduction by $\mathrm{CO}$ may be expressed as follows:

$$
\dot{R}_{i}^{\mathrm{CO}}=S_{\mathrm{f} i} n_{i} 4 \pi \bar{r}_{i}^{2} k_{i}^{\mathrm{CO}}\left(C_{\mathrm{CO}}-\frac{C_{\mathrm{CO}_{2}}}{K_{\mathrm{E} i}^{\mathrm{CO}}}\right)
$$

where 
Table 1. Values of 'activation energy' for rate of evolution of concerned volatile components. (Solomon and Colket, 1979)

\begin{tabular}{lcr}
\hline \multicolumn{1}{c}{ Component } & $\begin{array}{c}\text { Weight } \\
\text { fraction }\end{array}$ & $\begin{array}{c}\Delta E_{i}^{*} \\
(\mathrm{~J} / \mathrm{mol})\end{array}$ \\
\hline $\mathrm{CO}_{2}$ & 0.03 & 33472 \\
Loosely bound $\mathrm{CO}$ & 0.037 & 86190 \\
$\mathrm{H}_{2} \mathrm{O}$ & 0.055 & 41421 \\
Tightly bound $\mathrm{CO}$ & 0.046 & 100416 \\
Hydrocarbons $\left(\mathrm{CH}_{4}\right)$ & 0.034 & 81170 \\
$\mathrm{H}_{2}$ & 0.04 & 106274 \\
Tar & 0.12 & 66944 \\
\hline
\end{tabular}

$$
k_{i}^{\mathrm{co}}=k_{i 0}^{\mathrm{CO}} \operatorname{EXP}\left(\frac{-\Delta E_{i \mathrm{CO}}^{*}}{R T}\right)
$$

The rate equation for the reduction of the iron oxides by $\mathrm{H}_{2}$ has a similar form as in Eqs. (8) to (9).

\subsubsection{Coal Devolatilization}

The kinetics of coal devolatilization includes the information of rate of coal decomposition and the type and amount of individual gaseous products. According to Solomon and Colket, ${ }^{16)}$ the coal may be adequately assumed to be a compound made up of fixed carbon and volatile components: $\mathrm{CO}_{2}$, tightly bound $\mathrm{CO}, \mathrm{H}_{2} \mathrm{O}$, loosely bound $\mathrm{CO}$, hydrocarbons, $\mathrm{H}_{2}$ and tar. They also proposed that during the devolatilization, individual gas evolves from coal independently and simultaneously. The rate of evolution of individual volatile component may be assumed to be proportional to its weight fraction remaining in the char and expressed as follows ${ }^{16)}$ :

$$
\dot{R}_{\mathrm{v} i}=k_{\mathrm{v} i 0} \operatorname{EXP}\left(\frac{-\Delta E_{\mathrm{v} i}^{*}}{R T}\right) W_{\mathrm{v} i}
$$

where $\dot{R}_{v i}$ is the rate of evolution of volatile component $i$; and $W_{v i}$ is the remaining portion of volatile component $i$.

Solomon and Colket ${ }^{16)}$ extracted the temperature dependence and expressed as so called 'activation energy' for rate constants in the above equation from their experimental results based on 13 coals ranging in rank from a high volatile bituminous coal to lignite. These values are listed in Table $\mathbf{1}$ and used in the present work.

\subsubsection{Char Gasification}

Fixed carbon in char is oxidized simultaneously and independently by $\mathrm{CO}_{2}$ and $\mathrm{H}_{2} \mathrm{O}$ in the system. The total rate of char gasification is the sum of that by these two gaseous species as follows:

$$
\dot{R}_{\mathrm{c}}=\dot{R}_{\mathrm{c}}^{\mathrm{CO}_{2}}+\dot{R}_{\mathrm{c}}^{\mathrm{H}_{2} \mathrm{O}}
$$

where:

$$
\dot{R}_{\mathrm{c}}^{\mathrm{CO}_{2}}=S_{\mathrm{c}} n_{\mathrm{c}} 4 \pi \bar{r}_{\mathrm{c}}^{2} k_{\mathrm{c}}^{\mathrm{CO}_{2}}\left(C_{\mathrm{CO}_{2}}-\frac{C_{\mathrm{CO}}^{2}}{K_{\mathrm{E}_{\mathrm{c}}}^{\mathrm{CO}}}\right)
$$

and

$$
\dot{R}_{\mathrm{c}}^{\mathrm{H}_{2} \mathrm{O}}=S_{\mathrm{c}} n_{\mathrm{c}} 4 \pi \bar{r}_{\mathrm{c}}^{2} k_{\mathrm{c}}^{\mathrm{H}_{2} \mathrm{O}}\left(C_{\mathrm{H}_{2} \mathrm{O}}-\frac{C_{\mathrm{CO}} \times C_{\mathrm{H}_{2} \mathrm{O}}}{K_{\mathrm{Ec}}^{\mathrm{H}_{2} \mathrm{O}}}\right) \ldots
$$

The temperature dependence of rate constants in Eqs. (12) and (13) are defined in a similar way as that in Eq. (9).

The size of a coal or char particle may change due to swelling and contraction during devolatilization.

According to experimental observations, ${ }^{17)}$ swelling of coking coals usually starts at temperatures of 350 to $400^{\circ} \mathrm{C}$, begins to contract at around $650^{\circ} \mathrm{C}$ and ends at about $1000^{\circ} \mathrm{C}$. The general pattern of coal particle size versus temperature with a typical heating rate for this type of investigation is approximated following a normal distribution curve peaked at $650^{\circ} \mathrm{C}$, as expressed by the following equation.

$$
\bar{r}_{\mathrm{c}}=\bar{r}_{\mathrm{c}}^{\mathrm{o}}\left(1+\gamma \times \exp \left(\frac{-(T-650)^{2}}{2 \times 300^{2}}\right)\right)
$$

where $\gamma$ is a constant, and extracted in present model to be 0.18 by comparison of experimental data with computational results.

\subsection{Mass Balance for Individual Gaseous Species}

Gaseous species in the reacting system are products of Reactions (2) through (6), and mainly $\mathrm{CO}, \mathrm{CO}_{2}, \mathrm{H}_{2}$, $\mathrm{H}_{2} \mathrm{O}, \mathrm{CH}_{4}$ and tar. The presence of any other chemical species in a very minor amount is ignored in this analysis. The mass balance of these six major gaseous species are expressed as

$$
\frac{\partial}{\partial t}\left(\phi \rho_{j}\right)=\frac{\partial}{\partial x}\left(\frac{\phi}{\tau} D_{\text {eff } j} \frac{\partial \rho_{j}}{\partial x}\right)-\frac{\partial}{\partial x}\left(\rho_{j} v_{0}\right)-\sum_{i} \dot{N}_{i j} M_{j}
$$

Effective diffusivity of a species $j$ in a gaseous mixture, $D_{\text {eff } j}$, can be estimated from the knowledge of all of the relevant binary diffusion coefficients $D_{i j}$ by following equation $^{18)}$

$$
D_{\text {eff } j}=\left(1-y_{j}\right)\left[\sum_{\substack{i=1 \\ i \neq j)}} \frac{y_{i}}{D_{i j}}\right]^{-1}
$$

\subsection{Continuity and Momentum Equations and the Equation of State in the Gaseous Phase}

In the present system, gases are necessary intermediate reactants to sustain the overall chemical reactions, and gas flow contributes to convective heat and mass transfer. Continuity equation, momentum equation, and equation of state are established to calculate gaseous pressure, flow velocity and composition.

\subsubsection{Continuity Equation}

By summing six mass balance equations (Eq. (15)), the continuity equation may be obtained as follows:

$$
\frac{\partial}{\partial t}\left(\phi \rho_{\mathrm{g}}\right)=-\sum_{j} \sum_{i} \dot{N}_{i j} M_{j}-\frac{\partial}{\partial x}\left(\rho_{\mathrm{g}} V_{\mathrm{o}}\right)
$$

\subsubsection{Momentum Equation}

The rate of momentum change of a fluid flowing through the void space of a solid packing is the result of all external forces, i.e. pressure, gravity and frictional forces. In the present study, gases which are generated within the system flow through a solid packing of $28 \mathrm{~mm}$ height. By comparison, the contribution of gravity may be neglected without introducing significant error in 
modelling. The frictional force acting on the gaseous phase by the packing may be expressed as in Ergun Equation ${ }^{19,20)}$ :

$$
f_{\mathrm{r}}=\alpha \mu V_{\mathrm{o}}+\beta \rho_{\mathrm{g}} V_{\mathrm{o}}^{2}
$$

where $\alpha$ and $\beta$ are functions of properties of the packing,

$$
\alpha=150 \frac{(1-\phi)^{2}}{\phi^{3}\left(S_{\mathrm{fa}} d_{\mathrm{p}}\right)^{2}}
$$

and

$$
\beta=1.75 \frac{(1-\phi)}{\phi^{3}\left(S_{\mathrm{fa}} d_{P}\right)}
$$

Therefore, the momentum equation in the control volume may be expressed as follows:

$$
\frac{\partial}{\partial t}\left(\rho_{\mathrm{g}} \frac{V_{\mathrm{o}}}{\phi}\right)=-\frac{\partial P}{\partial x}-\frac{\partial}{\partial x}\left(\rho_{\mathrm{g}} \frac{V_{\mathrm{o}}^{2}}{\phi^{2}}\right)-\alpha \mu V_{\mathrm{o}}-\beta \rho_{\mathrm{g}} V_{\mathrm{o}}^{2}
$$

According to a numerical estimation, ${ }^{13)}$ extreme values of the second and the fourth terms on the right hand side of the above equation are at least two orders of magnitude smaller than the first and the third terms. Thus the second and fourth terms of the equation may be neglected in the computation in the present work without introducing significant errors. The momentum equation may be simpiified to become Eq. (22)

$$
\frac{\partial}{\partial t}\left(\rho_{\mathrm{g}} \frac{V_{\mathrm{o}}}{\phi}\right)=-\frac{\partial P}{\partial x}-\alpha \mu V_{\mathrm{o}}
$$

The viscosity of the gaseous mixture in the above equation can be estimated by Eq. $(23)^{18)}$

$$
\mu=\frac{\sum_{j} M_{j}^{1 / 2} y_{j} \mu_{j}}{\sum_{j} M_{j}^{1 / 2} y_{j}}
$$

\subsubsection{Equation of State of Ideal Gases}

Gas density varies with temperature and pressure. For the ranges of temperature and pressure values observed in the present system, the gases may be considered as incompressible and obey ideal gas law:

$$
P=\frac{\rho_{\mathrm{g}}}{\bar{M}_{\mathrm{g}}} R T
$$

\subsubsection{Summary}

There are 19 independent equations, namely Eq. (1); rate equations for Reactions (2) to (4) and (2A) to (4A), (5), (6) and (6A); Eq. (15) for all six gases; Eqs. (17), (22) and (24). Values of physical parameters such as $K_{\text {eff }}$, $C_{\mathrm{p}}, \rho$ and $\mu$ are taken from literature. On the other hand, values of chemical parameters, except devolatilization, are to be determined in the present work.

\subsection{Initial and Boundary Conditions}

\begin{tabular}{|c|c|c|c|c|c|c|}
\hline \multicolumn{3}{|c|}{ Iron ore particles } & \multicolumn{3}{|c|}{ Coal particles } & \multirow{2}{*}{$\begin{array}{c}\begin{array}{c}\text { Packed } \\
\text { bed }\end{array} \\
\text { Void } \\
\text { fraction }\end{array}$} \\
\hline $\begin{array}{c}\text { Number } \\
\text { density } \\
\left(\mathrm{m}^{-3}\right)\end{array}$ & $\begin{array}{c}\text { Average } \\
\text { diameter } \\
\text { (m) }\end{array}$ & $\begin{array}{l}\text { Shape } \\
\text { factor }\end{array}$ & $\begin{array}{c}\text { Number } \\
\text { density } \\
\left(m^{-3}\right)\end{array}$ & $\begin{array}{c}\text { Average } \\
\text { diameler } \\
\text { (m) }\end{array}$ & $\begin{array}{l}\text { Shape } \\
\text { factor }\end{array}$ & \\
\hline $1.02 \mathrm{E} 10$ & $3.9 \mathrm{E}-5$ & 1.75 & $1.61 \mathrm{E} 9$ & $6.9 \mathrm{E}-5$ & 1.37 & 0.405 \\
\hline
\end{tabular}

\subsubsection{Initial Conditions}

In most of experiments conducted, the ore and coal ratio was $80 / 20$ by weight, and packed in a stainless steel crucible with an initial packing density of $1900 \mathrm{~kg} / \mathrm{m}^{3}$.
Table 2. Initial properties of solid materials and the packed bed.

Initial conditions for the present model are specified according to this initial experimental condition unless otherwise specified.

The initial number density, average size and shape factor of the ore and the coal particles, and initial void fraction of the packed bed are listed in Table 2.

When ore and coal were mixed and packed in the crucible in air at ambient temperature, the initial condition may be expressed as

$$
\text { When } \begin{aligned}
t & =0,0 \leq x \leq 0.028(\mathrm{~m}) \\
T & =298.16 \mathrm{~K} \\
V_{0} & =0 \mathrm{~m} / \mathrm{sec} \\
P & =1.0133 \times 10^{5} \mathrm{~Pa} \\
\rho_{j} & =0 \mathrm{~kg} / \mathrm{m}^{3}\left(j=\mathrm{CO}, \mathrm{CO}_{2}, \mathrm{H}_{2}, \mathrm{H}_{2} \mathrm{O}, \mathrm{CH}_{4}\right. \text { and }
\end{aligned}
$$$$
\text { tar) }
$$

\subsubsection{Boundary Conditions}

The present one-dimensional reaction system has two boundaries; the bottom and the top face of the packed bed.

a. Boundary Conditions at the Hot Face

when $x=0, t>0$

$T=T_{1}$ which is directly measured on a continuous basis;

$$
V_{0}=0 \mathrm{~m} / \mathrm{s} ; \text { and, }
$$

b. Boundary Conditions at the Top Face

$$
\begin{gathered}
\text { at } x=0.028(\mathrm{~m}), t>0 \\
P=1.0133 \times 10^{5} \mathrm{~Pa} ; \text { and }, \\
\rho_{\mathrm{g}}=\frac{P \bar{M}_{\mathrm{g}}}{R T}, \mathrm{~kg} / \mathrm{m}^{3} \ldots \ldots \ldots . . . \\
\dot{q}_{\mathrm{rad}}=-F_{\mathrm{sm}} \varepsilon_{\mathrm{m}} \sigma\left(T^{4}-T_{\text {ambient }}^{4}\right)
\end{gathered}
$$

where $F_{\mathrm{sm}}$ is a view factor for the top face of packed bed and the opening of the crucible. It was calculated according to this configuration to be $0.25 .^{21)} \varepsilon_{\mathrm{m}}$ is emissivity of mixture, and may be assumed to be 0.85 according to the above quote reference; while $\sigma$ is the StefanBoltzmann constant $\left(=5.6651 \times 10^{-8} \mathrm{~J} / \mathrm{s} \cdot \mathrm{m}^{2} \cdot \mathrm{k}^{4}\right)$.

\section{Computational Results and Model Validation}

The equations in present model have to be solved simultaneously by numerical methods to obtain local values of the various dependent variables as functions of $x$ and $t$. The explicit finite difference method was used to solve these equations numerically on a personal computer. The procedure of numerical computation is shown in Fig. 6. The computation stopped at the sixtieth minute which is the longest reaction time for the 


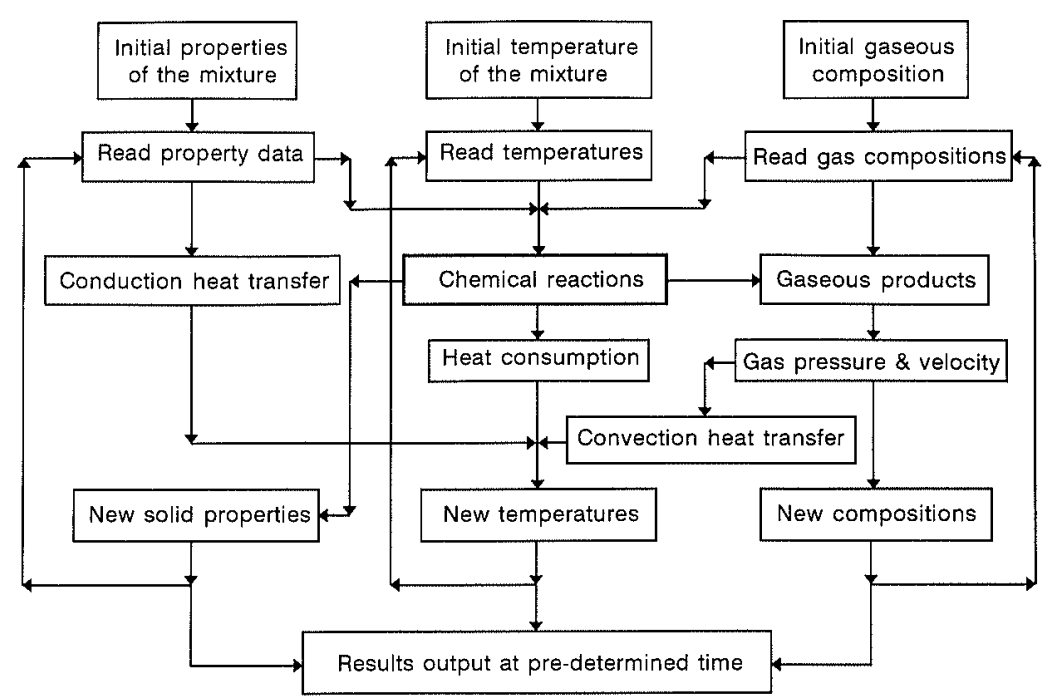

Fig. 6. Computation procedure of the model.

Table 3. Values of parameters used for calculation of rate constants of reactions.

\begin{tabular}{ccccccccc}
\hline Reactions & $\begin{array}{c}\mathrm{Fe}_{3} \mathrm{O}_{4}-\mathrm{FeO} \\
\text { by CO }\end{array}$ & $\begin{array}{c}\mathrm{FeO}-\mathrm{Fe} \\
\text { by CO }\end{array}$ & $\begin{array}{c}\mathrm{Fe}_{3} \mathrm{O}_{4}-\mathrm{Fe} \\
\text { by CO }\end{array}$ & $\begin{array}{c}\mathrm{Fe}_{3} \mathrm{O}_{4}-\mathrm{FeO} \\
\text { by } \mathrm{H}_{2}\end{array}$ & $\begin{array}{c}\mathrm{FeO}-\mathrm{Fe} \\
\text { by } \mathrm{H}_{2}\end{array}$ & $\begin{array}{c}\mathrm{Fe}_{3} \mathrm{O}_{4}-\mathrm{Fe} \\
\text { by } \mathrm{H}_{2}\end{array}$ & $\begin{array}{c}\mathrm{C} \text { gasification } \\
\text { by } \mathrm{CO}_{2}\end{array}$ & $\begin{array}{c}\mathrm{C} \text { gasification } \\
\text { by } \mathrm{H}_{2} \mathrm{O}\end{array}$ \\
\hline $\begin{array}{c}k_{j 0} \\
\Delta E_{i}^{*}(\mathrm{~J} / \mathrm{mol})\end{array}$ & 10.7 & 59.0 & 16.0 & 11.0 & 20.0 & 6.5 & $1.87 \mathrm{E} 8$ & $6.0 \mathrm{E} 5$ \\
\end{tabular}

experiments conducted.

\subsection{The Evaluation of Rate Constants of Iron Oxide Reduction and Char Gasification}

Table 3 shows the values of parameters used for calculation of rate constants for reactions, they were obtained by best curve-fitting which will be discussed later. The plot of rate constants against the reciprocal temperature for reduction of $\mathrm{FeO}$ by $\mathrm{CO}$ is shown in Fig. 7 as an example for discussion, that for other reactions can be found in Ref. 13).

The values of rate constants for iron oxide reduction obtained in the present work fall within the ranges of the reported literature values which used different experimental techniques to determinate the interfacial area. These are two commonly used methods, one is based on topochemical pattern in the progress of the reacting interface and the other is the direct measurement by B.E. T. method. Based on the kinetic expression shown in Eqs. (8) to (10), the values of $k_{i}\left(4 \pi r_{0}^{2}\right)$ may be extracted from data first, then, the rate constant is determinated with the knowledge of gas-solid interfacial area. A topochemical calculation under-estimates the interfacial area by replacing irregular surface with the geometric surface of a sphere for a gas-solid system, and thus over-estimates the values of the rate constant. On the other hand, the B.E.T. method over-estimates the interfacial area by including all internal surface which may not participate in a chemical reaction, and thus under-estimates the values of the rate constant. It is reasonable to expect that values of rate constants which represent the data the best are in between the reported values in the literature as shown in Fig. 7.

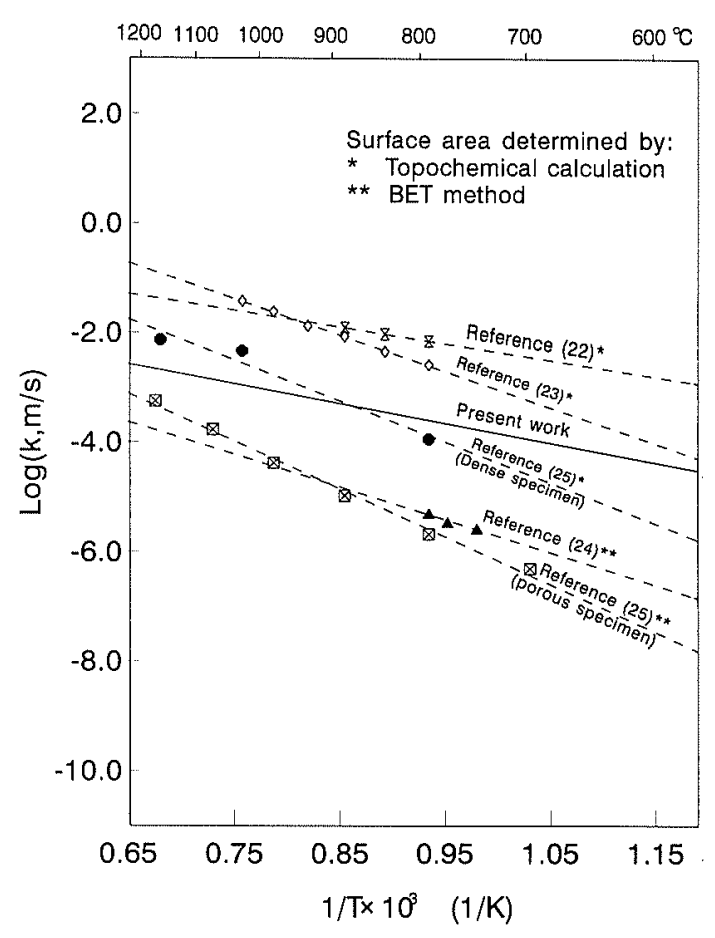

Fig. 7. Plot of rate constants against the reciprocal temperature for reduction of $\mathrm{FeO}$ by $\mathrm{CO}$.

\subsection{Comparison between Computational Results and Experimental Data}

The mathematical model described above is used to calculate changes in the system as functions of location and reaction time. The case with furnace temperature set at $1200^{\circ} \mathrm{C}$ and ore/coal ratio of $80 / 20$ by weight is present in this section as follows. 


\subsubsection{Temperature Profiles}

Computed local temperatures as functions of reaction time and location are shown as solid curves in Fig. 2. The computed temperatures are in good agreement with measured temperatures which are shown as points and connected by dotted lines in the figure, particularly after about $20 \mathrm{~min}$ of reaction time. Before the twentieth minute, the computed values of temperature at locations farther away from the hot surface are higher than that measured, especially in locations 3, 4, and 5. It is likely due to water vapour originated from higher temperature regions (such as locations 1 and 2), condenses and later re-vaporizes. The present model does not include the heat exchange due to water vapour condensation and re-vaporization, thus has a higher values of computed temperatures.

\subsubsection{Reduction of Iron Oxides and Degree of Re- duction}

Computed local degrees of metallization and degree of iron oxide reduction as functions of time are shown in Fig. 3. In this figure, the computed values for the degree of reduction of iron oxide in location 1 is higher than that measured, and the opposite is true in locations away from the hot face. It may be due to that part of iron oxides reacts with the gangue at higher temperature to form a slag phase and lowers its reactivity for reduction. The present model does not include the effect of slag formation on the rate of reduction, thus resulting in a disagreement in degrees of metallization and reduction of iron oxide at high temperatures as shown in Fig. 3.

\subsubsection{Degree of Carbon Gasification}

Figure 4 shows the computed and measured values for the degree of carbon gasification as functions of location and reaction time. The lower computed values $v s$. the measured ones at $20 \mathrm{~min}$ at locations 3, 4 and 5 may be due to our inability to stop the coal devolatilization instantaneously at the end of an experiment, even though the crucible containing the reacting ore/coal mixture was quickly removed from furnace and quenched by running water. Obviously, it took a certain finite time to cool down the interior locations 3,4 and 5 .

The higher computed value of carbon gasification in location 2 may result from the error of average radius for coal particles in this location. It was assumed that the average radius of char particles increased due to swelling during the heating, thus results in a higher rate of carbon gasification.

\subsubsection{Pressures and Gas Flow Velocity}

Figure 5 shows computed and measured gas pressures as functions of location and reaction time when the furnace temperatures were set at $1200^{\circ} \mathrm{C}$. The measured values are the resultant pressure due to the rates of gas generation by chemical reactions and removal by viscous flow at a given location. The changes in pore structure, such as crack formation, would have a pronounced effect on the rate of removal of gases, i.e. it lowers the pressure building up. Thus, it is not expected to have calculated

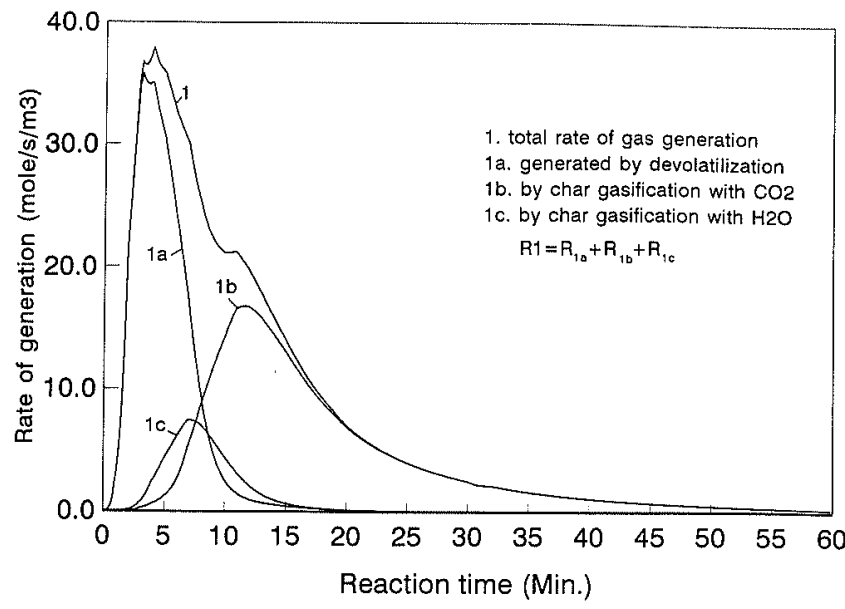

Fig. 8. Computed local rate of gas generation by devolatilization of coal and gasification of char at location 1 $\left(\right.$ Ore $/ \mathrm{coal}=80 / 20$, furnace temperature $=1200^{\circ} \mathrm{C}$ )

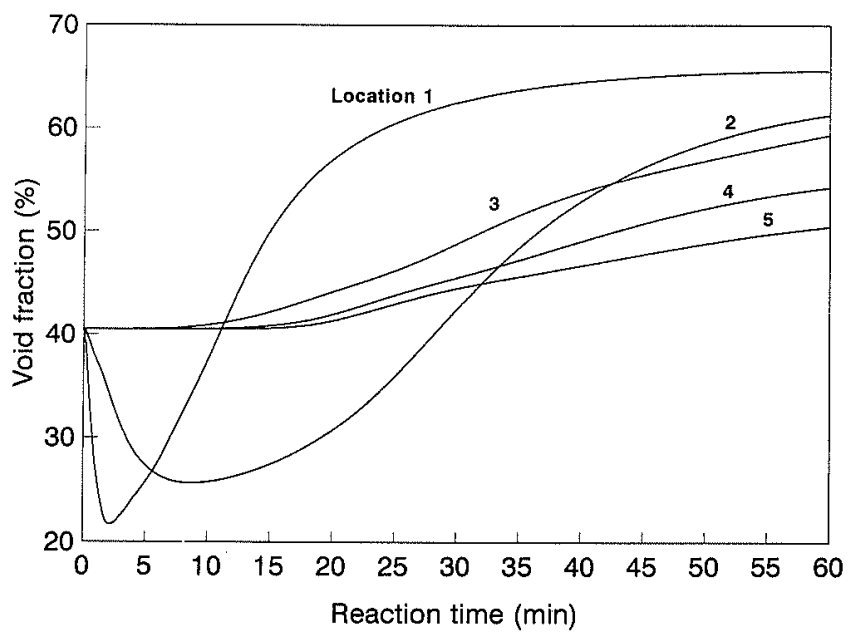

Fig. 9. Computed local void fraction of the packing as a function of reaction time (Ore/coal $=80 / 20$, furnace temperature $=1200^{\circ} \mathrm{C}$ )

values to closely match these measured values in all regions at all time because cracks in reacted specimens are very common occurrence. However, the computed pressures have the similar pattern as observed in experiments.

The computed pressure peaks within the first $20 \mathrm{~min}$ are most likely resulting from high rates of gas generation and the lower void fraction of the packing during devolatilization of coal. The computed local rate of gas generation at location 1 as a function of reaction time are shown in Fig. 8, and the void fraction of packing in Fig. 9. The higher values of gas generation and lower in void space around $5 \mathrm{~min}$ of reaction time at this location are the main causes for the high pressure developed. The decrease of void fraction in locations 1 and 2 is due to swelling of the coal particles under the high heating rate.

\subsection{Efforts in the Validation of the Model}

The mathematical model developed in Sec. 3 with the same set of values of kinetic parameters has been applied to additional three sets of experiments which are independent of that reported in Sec. 4.2 and Figs. 2 to 5. One set of experiments was carried out with furnace 


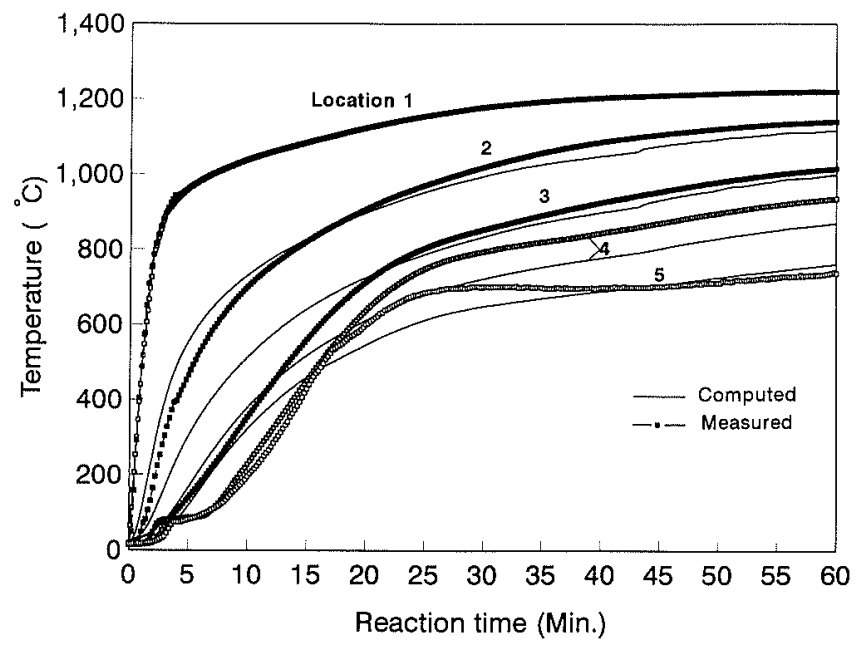

Fig. 10. Measured and computed local temperature as a function of reaction time (Ore/coal $=80 / 20$, furnace temperature $=1300^{\circ} \mathrm{C}$ ).

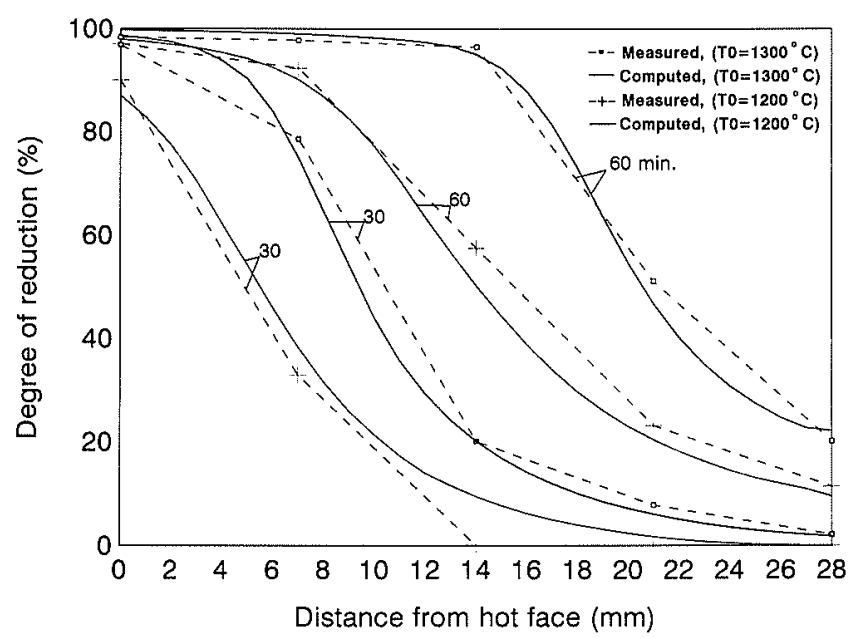

Fig. 11. Effect of furnace temperature on degree of iron ore reduction (Ore/coal $=80 / 20$ ).

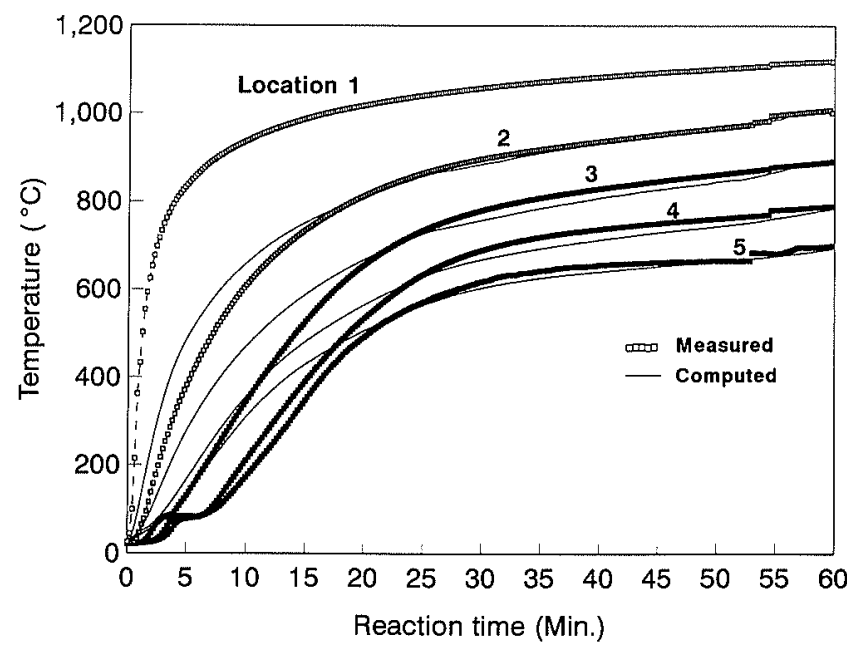

Fig. 12. Computed and measured local temperature as a function of reaction time (Ore/coal $=82 / 18$, furnace temperature $=1200^{\circ} \mathrm{C}$ ).

temperature at $1300^{\circ} \mathrm{C}$ and ore/coal ratio of $80 / 20$, and other two with furnace temperature at $1200^{\circ} \mathrm{C}$ but with ore/coal ratios of $82 / 18$ and $85 / 15$, respectively. Other than the change in temperature or ore/coal ratio, all

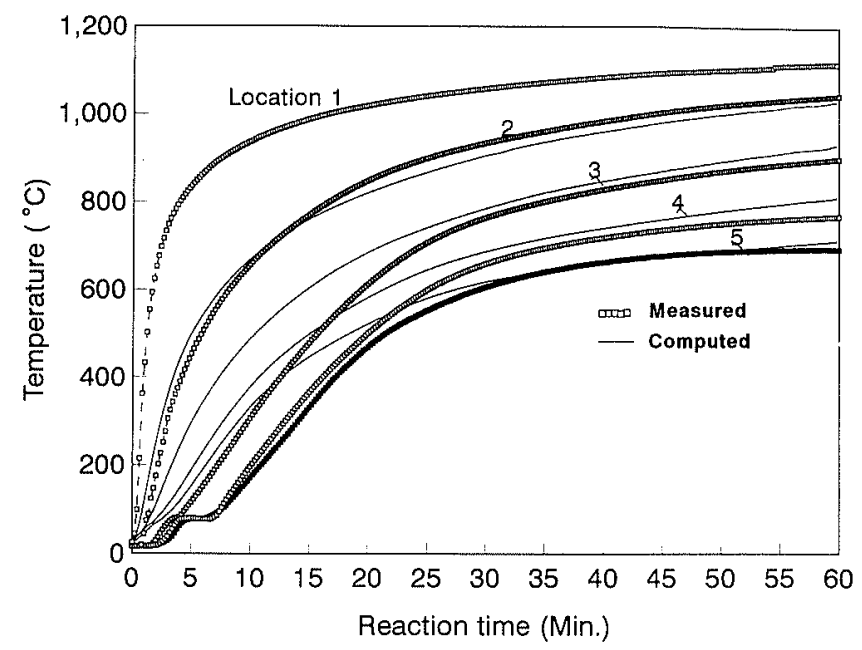

Fig. 13. Computed and measured local temperatures as a function of reaction time (Ore/coal $=85 / 15$, furnace temperature $=1200^{\circ} \mathrm{C}$ )

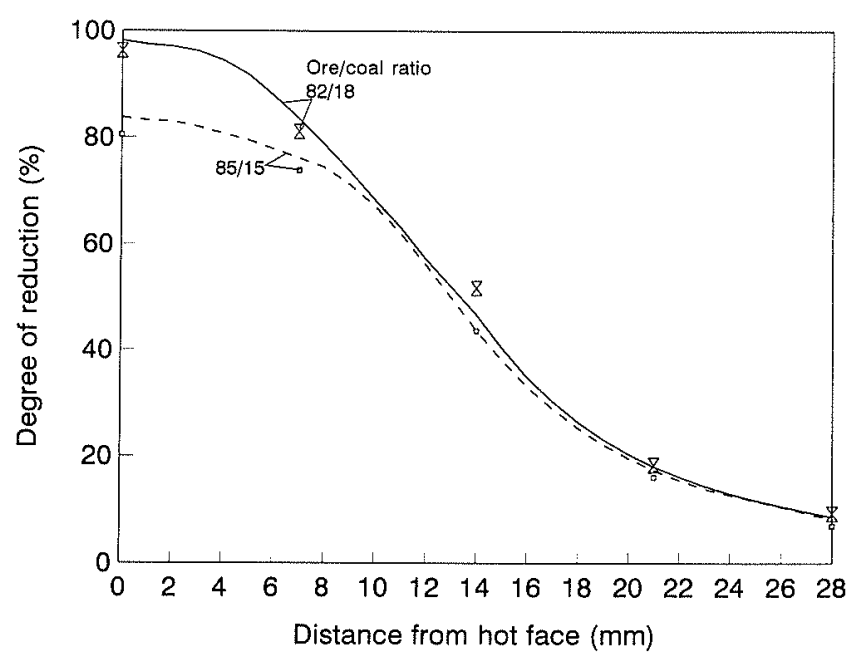

Fig. 14. Measured profiles of degree of iron ore reduction over the height of the packing ( 2 ore/coal ratios, furnace temperature $=1200^{\circ} \mathrm{C}$, reaction time $=60 \mathrm{~min}$ ).

remaining experimental conditions in these three sets of experiments were the same as in the set from which values of parameters in the model were extracted. Due to the length of the paper, only data of temperature and degree of reduction under these experimental conditions are shown here as Figs. 10 to 14, details of other results can be found elsewhere. ${ }^{13)}$

In Figs. 10 to 14, general agreement exists between the computed and measured temperatures, the degree of reduction as functions of reaction time and location. These results illustrate that this mathematical model developed in the present work is capable of representing the behaviours observed in this system.

\section{Conclusion}

A non-isothermal and non-isobaric mathematical model has been developed for the study of reactions in the iron ore/coal composite. It includes: one equation of thermal energy balance, nine kinetic expressions for heterogeneous reactions, six equations of mass balance for gaseous species, one continuity equation, one mo- 
mentum equation and one equation of state for ideal gases. Rate constants of chemical reactions were determined from one set of data and then, the model was tested successfully with other three sets of independent data obtained under different experimental conditions. These results illustrate that this mathematical model, including the values of rate constants shown in Table 3 , is capable of representing the behaviours experimentally observed in the present work.

\section{Acknowledgements}

The authors are grateful for financial support provided by Natural Science and Engineering Research Council of Canada in the form of a research grant to W.-K. Lu.

\section{Nomenclature}

$C_{\mathrm{CO}}:$ concentration of $\mathrm{CO}\left(\mathrm{mol} / \mathrm{m}^{3}\right)$

$C_{\mathrm{CO}_{2}}$ : concentration of $\mathrm{CO}_{2}\left(\mathrm{~mol} / \mathrm{m}^{3}\right)$

$C_{\mathrm{H}_{2}}$ : concentration of $\mathrm{H}_{2}\left(\mathrm{~mol} / \mathrm{m}^{3}\right)$

$C_{\mathrm{H}_{2} \mathrm{O}}$ : concentration of $\mathrm{H}_{2} \mathrm{O}\left(\mathrm{mol} / \mathrm{m}^{3}\right)$

$C_{\mathrm{pm}}$ : specific heat of the solid mixture $(\mathrm{J} / \mathrm{kg} / \mathrm{K})$

$C_{\mathrm{pg}}:$ specific heat of the gas $(\mathrm{J} / \mathrm{kg} / \mathrm{K})$

$D_{\text {eff } j}$ : effective diffusivity of species $j$ in the gaseous phase $\left(\mathrm{m}^{2} / \mathrm{s}\right)$

$d_{\mathrm{p}}$ : average diameter of the particle $(\mathrm{m})$

$\Delta E_{i}^{*}$ : 'activation energy' of reaction $i(\mathrm{~J} / \mathrm{mol})$

$f_{\mathrm{m} i}$ : volume fraction of component $i$ in the control volume

$f_{\mathrm{r}}$ : frictional force acting on gas by packed bed $\left(\mathrm{N} / \mathrm{m}^{3}\right)$

$F_{\text {sm }}$ : view factor for top face of the packed bed and the mouth of crucible

$\Delta G^{\circ}:$ standard free energy change of the reaction

$H$ : enthalpy $\left(\mathrm{J} / \mathrm{m}^{3}\right)$

$\Delta H_{i}:$ heat of chemical reaction $i(\mathrm{~J} / \mathrm{mol})$

$k_{i}$ : rate constant for reaction $i$

$k_{i 0}$ : pre-exponential constant in rate constant for reaction $i$

$K_{\mathrm{E} i}: \quad$ equilibrium constant for reaction $i$

$K_{\text {eff } \mathrm{m}}$ : effective thermal conductivity of the mixture $(\mathrm{W} / \mathrm{m} / \mathrm{K})$

$L:$ height of packed bed (m)

$M_{j}$ : molecular weight of the gaseous species $j$ $(\mathrm{kg} / \mathrm{mol})$

$M_{\mathrm{m}}$ : mean molecular weight of the gaseous mixture $(\mathrm{kg} / \mathrm{mol})$

$n_{i}:$ number of particles of solid reactant for reaction $i$ in the mixture $\left(\mathrm{m}^{-3}\right)$

$\dot{N}_{i j}$ : net rate of gaseous species $j$ consumed/generated by chemical reaction $i\left(\mathrm{~mol} / \mathrm{s} / \mathrm{m}^{3}\right)$

$P: \quad$ pressure $(\mathrm{Pa})$

$r:$ radius $(\mathrm{m})$

$\bar{r}_{i}$ : average radius of particle for reaction $i(\mathrm{~m})$

$\dot{R}_{i}: \quad$ rate of chemical reaction $i\left(\mathrm{~mol} / \mathrm{m}^{3} / \mathrm{s}\right)$

$R$ : gas constant $(8.314 \mathrm{~J} / \mathrm{mol} / \mathrm{K})$

$S_{\mathrm{f}}$ : shape factor of particles

$t:$ time (s)

$T:$ temperature $(\mathrm{K})$
$V_{\mathrm{a}}$ : average velocity of gas flow in the interstices of the packed bed $(\mathrm{m} / \mathrm{s})$

$V_{\mathrm{o}}:$ superficial gas velocity $\left(V_{\mathrm{a}} \phi\right)(\mathrm{m} / \mathrm{s})$

$W_{v i}: \quad$ un-evolved portion of volatile component $i$ $(\mathrm{kg} / \mathrm{kg}$-coal $)$

$x:$ distance $(\mathrm{m})$

$y_{j}$ : mole fraction of species $j$ in the gaseous phase $(\%)$

$\rho:$ density of a solid reactant $\left(\mathrm{kg} / \mathrm{m}^{3}\right)$

$\rho_{\mathrm{m}}$ : density of mixture $\left(\mathrm{kg} / \mathrm{m}^{3}\right)$

$\rho_{\mathrm{g}}:$ density of gas $\left(\mathrm{kg} / \mathrm{m}^{3}\right)$

$\rho_{j}$ : density of gaseous species $j\left(\mathrm{~kg} / \mathrm{m}^{3}\right)$

$\varphi$ : reacted fraction of iron oxide

$\phi:$ void fraction of the packed bed

$\varphi_{i}$ : reacted fraction of iron oxide $i$

$\mu:$ viscosity of fluid $(\mathrm{kg} / \mathrm{m} / \mathrm{s})$

$\tau:$ tortuosity factor

$\varepsilon$ : emissivity

$\sigma:$ Stefan-Boltzmann constant $\left(5.147 \times 10^{-10} \mathrm{~W} /\right.$ $\left.\mathrm{m}^{2} \cdot \mathrm{K}^{4}\right)$

\section{REFERENCES}

1) P. C. Ghosh and S. N. Tiwari: J. Iron Steel Inst., (1970), 255.

2) R. J. Fruehan: Metall. Trans. B, 8B (1977), 279.

3) K. Otsuka and D. Kunii: J. Chem. Eng. of Jpn., 2(1969), No. 1, 46.

4) R. Haque, H. S. Ray and A. Mukjerjee: Ironmaking Steelmaking, 19 (1992), No. 2, 127

5) R. Haque, H. S. Ray and A. Mukjerjee: Metall. Trans. B, 24B (1992), 511.

6) C. E. Seaton, J. S. Foster and J. Velasco: Trans. Iron Steel Inst. Jpn., 23 (1983), 490.

7) Y. K. Rao: Metall. Trans., 2 (1971), 1439.

8) N. S. Srinivasan and A. K. Lahiri: Metall. Trans. B, 8B (1977), 175

9) C. Bryk and W.-K. Lu: Ironmaking Steelmaking, 13 (1986), No. 2,70 .

10) D. Bandyopadhyay, N. Chakraborti and A. Ghosh: Steel Res., 64 (1993), No. 7, 340.

11) B.-H. Huang and W.-K. Lu: ISIJ Int., 33 (1993), 1055.

12) S. Sun and W.-K. Lu: ISIJ Int., 33 (1993), 1062.

13) S. Sun: Ph. D. Thesis, McMaster University, Hamilton, Ont., Canada, (1997).

14) S. Sun and W.-K. Lu: Ironmaking Conf. Proc., Vol. 55 (1996), Pitt, 645 .

15) S. Sun and W.-K. Lu: submitted to ISIJ Int. for publication.

16) P. R. Solomon and M. B. Colket: 17th Symp. (Int.) on Combustion, The Combustion Inst., Pittsburgh, (1979), 131.

17) R. Loison, A. Peytacy, A. F. Boyer and R. Grillot: Chemistry of Coal Utilization, Supplementary Volume, ed. by H. H. Lowry, John Wiley \& Sons, Inc., New York, (1963), 187.

18) D. E. Rosner: Transport Processes in Chemically Reacting Flow Systems, Butterworths Publishers, Boston, (1986), 109.

19) S. Ergun and A. A. Orning: Ind. Eng. Chem., 41 (1949), 1179

20) S. Ergun: Chem. Eng. Prog., 48 (1952), 89.

21) G. H. Geiger and D. R. Poirier: Transport Phenomena in Metallurgy, Addison-Wesley Publ. Co., Menlo Park, California, (1973), 469.

22) Q. T. Tsay, W. H. Ray and J. Szekely: $A I C h E J ., 22$ (1976), No. 6, 1064.

23) T. Murayama, Y. Ono and Y. Kawai: Trans. Iron Steel Inst. Jpn., 18 (1978), 579

24) S. P. Trushenski, K. Li and W. O. Phibrook: Metall. Trans., 5 (1974), 1149

25) E. T. Turkdogan and J. V. Vinters: Metall. Trans., 3 (1972), 1560 